\title{
Molecular detection of c-mpl thrombopoietin receptor gene expression in chronic myeloproliferative disorders
}

\author{
S Duensing, A Duensing, J G Meran, A Kreft, G Büsche, A Ganser, A Georgii
}

\begin{abstract}
Background-Chronic myeloproliferative disorders (CMPD) originate from a pluripotent haematopoietic progenitor cell but show a marked degree of heterogeneity, especially between Philadelphia chromosome positive and negative disease entities. Abnormal megakaryopoiesis is a frequent finding in CMPD, often associated with thrombocythaemic cell counts. Recent experimental data have suggested that the c-Mpl thrombopoietin receptor, together with its ligand thrombopoietin, are not only the major physiological regulators of megakaryopoiesis and platelet production, but also play a crucial role in chronic myeloproliferation.
\end{abstract}

Methods-A total of 18 peripheral blood mononuclear cell samples obtained from patients with CMPD (chronic myelocytic leukaemia (CML), n = 10; polycythaemia vera $(P V), n=6$; and primary thrombocythaemia (PTH), $\mathbf{n}=2$ ) were analysed for c-mpl mRNA using the reverse transcriptase polymerase chain reaction (RTPCR). In another 20 patients (CML, $\mathrm{n}=10$; chronic megakaryocytic granulocytic myelosis $(\mathbf{C M G M}), \mathbf{n}=3 ; \mathbf{P V}, \mathbf{n}=3$; PTH, $\mathbf{n}=4$ ), we compared the number of haematopoietic progenitors expressing c-Mpl, as characterised by coexpression with the CD34 antigen, in the bone marrow using double immunofluorescence staining.

Results-c-mpl mRNA was detected in all samples from patients with CML analysed, whereas only two of six PV and one of two PTH samples were positive $\left(p \leqslant 0.008 ; \chi^{2}\right.$ test $)$. Expression of the c-mpl receptor gene was absent in healthy subjects used as controls. Similarly, an increase of c-Mpl expressing CD34 positive haematopoietic cells was detected in seven of 10 bone marrow aspirates obtained from patients with CML. Increased numbers of $\mathrm{c}-\mathrm{Mpl}$ positive $\mathrm{CD} 34$ positive cells were found in only one of four patients with PTH, whereas in PV and CMGM the numbers of $\mathrm{c}-\mathrm{Mpl}$ positive CD34 positive cells did not exceed normal values, despite thrombocythaemic cell counts.

Conclusions-These data confirm recent findings showing an impaired expression of the c-mpl thrombopoietin receptor gene in Philadelphia chromosome nega- tive CMPD when compared with patients with Philadelphia chromosome positive CML. The relevance of this observation to the functional and morphological characteristics of abnormal megakaryopoiesis remains unclear. Thrombocythaemic cell counts and a mature phenotype in megakaryocytes occur frequently in Philadelphia chromosome negative CMPD but require an intact $\mathrm{c}-\mathrm{Mpl}$ receptor under physiological conditions. Therefore, further studies are warranted to elucidate the mechanisms contributing to megakaryopoiesis in CMPD disease entities with decreased c-mpl gene expression. (F Clin Pathol: Mol Pathol 1999;52:146-150)

Keywords: c-Mpl thrombopoietin receptor; chronic myeloproliferative disorders; megakaryopoiesis

Thrombocythaemic platelet counts in the peripheral blood are not restricted to essential or primary thrombocythaemia (PTH) but may occur in patients with polycythaemia vera (PV), chronic idiopathic myelofibrosis (CIMF) or even in Philadelphia chromosome positive chronic myelocytic leukaemia (CML) in a substantial number of patients. ${ }^{2}{ }^{2}$ Dysplastic cytomorphology and a large increase in the numbers of megakaryocytes are seen in trephine biopsies of bone marrows from haematologically diagnosed chronic myeloproliferative disorders (CMPD), including CML. ${ }^{34}$ Spontaneous in vitro formation of megakaryocytic colonies from peripheral blood or bone marrow has frequently been reported in CMPD and has been said to reflect the growth characteristics of the malignant clone..$^{5-8}$ However, the mechanisms involved in this phenomenon, as well as in abnormal megakaryopoiesis, are not understood in detail.

The c-Mpl thrombopoietin receptor and its ligand, thrombopoietin, are the major physiological regulators of megakaryopoiesis and platelet production. ${ }^{9}$ Thrombopoietin acts predominantly on the later stages of megakaryopoiesis, thus inducing large and highly polyploid megakaryocytes, which form specific granules and break up into platelets. ${ }^{9}$ Recent experiments demonstrated that thrombopoietin also affects primitive haematopoietic precursors not yet committed to the megakaryocytic lineage. ${ }^{10}$ The c-mpl gene has been found to be the human homologue of $\mathrm{v}$-mpl, the oncogene of the murine myeloproliferative leukaemia virus (MPLV), ${ }^{11}$ which induces thrombocytosis, erythrocytosis, granulocytosis, and splenomegaly in mice. ${ }^{12}$ Further experi- 
Table 1 Expression of c-mpl $m R N A$ in peripheral blood samples of patients with chronic myeloproliferative disorders

\begin{tabular}{|c|c|c|c|c|c|c|c|c|}
\hline Patient & Diagnosis & $\operatorname{Sex}(M / F)$ & Age (years) & $\begin{array}{l}W B C \\
\left(\times 10^{9} / l\right)\end{array}$ & $H b(g / l)$ & Plt $\left(\times 10^{9} / l\right)$ & Treatment & $\begin{array}{l}c-m p l \\
m R N A\end{array}$ \\
\hline 1 & CML & M & 22 & 24.5 & 115 & 364 & No & + \\
\hline 2 & CML & $\mathrm{F}$ & 71 & 5.4 & 120 & 231 & Yes* & + \\
\hline 3 & CML & M & 27 & 435 & 58 & 673 & Yes` & + \\
\hline 4 & CML & $M$ & 45 & 34 & 110 & 226 & Yes $^{\star}$ & + \\
\hline 5 & CML & M & 57 & 23 & 95 & 3 & Yes $\star \S$ & + \\
\hline 6 & CML & M & 27 & 30.4 & 151 & 11 & Yes* & + \\
\hline 7 & CML & M & 25 & 157 & 85 & 615 & Yes $\star s$ & + \\
\hline 8 & CML & M & 20 & 117 & 100 & 450 & Yes* & + \\
\hline 9 & CML & $M$ & 62 & 6.3 & 44 & 376 & Yes* & + \\
\hline 10 & CML & M & 31 & 5.3 & 133 & 135 & No & + \\
\hline 11 & PV & $\mathrm{F}$ & 71 & 5.8 & 142 & 508 & Yes* & - \\
\hline 12 & PV & $\mathrm{F}$ & 59 & 14.1 & 151 & 735 & Yes* & - \\
\hline 13 & PV & $\mathrm{F}$ & 48 & 5.1 & 120 & 268 & No & - \\
\hline 14 & PV & M & 70 & 7.9 & 175 & 230 & No & - \\
\hline 15 & PV & $M$ & 51 & 5.9 & 130 & 639 & Yes` & + \\
\hline 16 & PV & $\mathrm{F}$ & 56 & 8.6 & 147 & 604 & Yes` & + \\
\hline 17 & PTH & $\mathrm{F}$ & 61 & 5.4 & 129 & 224 & Yes" & - \\
\hline 18 & PTH & $\mathrm{F}$ & 69 & 2.3 & 79 & 457 & Yes $^{\star}$ & + \\
\hline
\end{tabular}

CML, chronic myelocytic leukaemia; PTH, primary thrombocythaemia; PV, polycythaemia vera; M, male; F, female; WBC, white blood cells; Hb, haemoglobin; Plt, platelets.

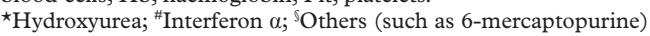

ments showed that overexpression of the thrombopoietin gene in the animal model not only induced multilineage growth of blood cells but also extramedullary haematopoiesis and myelofibrosis similar to chronic myeloproliferation in humans. ${ }^{13-15}$ There is also evidence that c-mpl contributes to abnormal megakaryopoiesis. In patients with CMPD, Li et al found a decrease in spontaneous megakaryocytic colonies from peripheral blood using antisense strategies against the c-mpl receptor gene. ${ }^{16}$

With regard to these data, some interest arises in abnormalities of thrombopoietin mediated signalling through the $\mathrm{c}-\mathrm{Mpl}$ receptor and the distribution of the receptor itself in CMPD. To evaluate potential differences between CMPD disease entities, we compared peripheral blood c-mpl mRNA expression between patients with Philadelphia chromosome positive CML and those with PV or PTH. The observed differences between CML and Philadelphia chromosome negative disorders were further investigated by studying the distribution of $\mathrm{c}-\mathrm{Mpl}$ positive haematopoietic progenitors in the bone marrow of patients with CMPD.

\section{Material and methods}

PATIENTS AND HISTOPATHOLOGY

Peripheral blood samples were collected from a total of 18 patients with CMPD (CML, $\mathrm{n}=10 ; \mathrm{PV}, \mathrm{n}=6 ; \mathrm{PTH}, \mathrm{n}=2$; table 1 ) and eight healthy subjects (not shown) after informed consent. The mean age of the patients was 48 years (range, 20-71 years). Because bone marrow aspirates were not collected from these patients, we analysed the distribution of $\mathrm{c}-\mathrm{Mpl}$ expressing haematopoietic progenitors in a second group of 20 patients with CMPD (CML, $\mathrm{n}=10$; chronic megakaryocytic granulocytic myelosis (CMGM), $\mathrm{n}=3$; $\mathrm{PV}, \mathrm{n}=3$; PTH, $\mathrm{n}=4$; table 2) and eight patients lacking histopathological alterations used as controls (data not shown). The mean age of patients with CMPD in the latter group was 59 years (range, 35-84 years).

Haematological diagnoses were confirmed by histopathology of trephine biopsies from the bone marrow. Histopathological classification was performed by two observers, according to the Hannover system. ${ }^{2}$ This may deviate from the new WHO nomenclature in early cases of CIMF, which are included among the descrip-

Table 2 Increase of $\mathrm{c}-\mathrm{Mpl} / \mathrm{CD} 34$ positive cells in the bone marrow of patients with chronic myeloproliferative disorders

\begin{tabular}{|c|c|c|c|c|c|c|c|c|c|c|}
\hline Patient & Diagnosis & $\begin{array}{l}\operatorname{Sex} \\
(M / F)\end{array}$ & $\begin{array}{l}\text { Age } \\
\text { (years) }\end{array}$ & $\begin{array}{l}W B C \\
\left(\times 10^{9} / l\right)\end{array}$ & $\begin{array}{l}\mathrm{Hb} \\
(\mathrm{g} / \mathrm{l})\end{array}$ & $\begin{array}{l}\text { Platelets } \\
\left(\times 10^{9} / l\right)\end{array}$ & Treatment & $\begin{array}{l}\text { Marrow } \\
\text { fibrosis }\end{array}$ & $\begin{array}{l}\text { Increase of } \\
\text { megakaryocytes }\end{array}$ & $\begin{array}{l}\text { Increase of } \\
c-m p l^{+} / C D 34^{+} \text {cells }\end{array}$ \\
\hline 1 & CML & M & 43 & 4.3 & 119 & 54 & Yes* & - & - & - \\
\hline 2 & $\mathrm{CML}$ & $M$ & 35 & 179 & 99 & 213 & No & - & + & + \\
\hline 3 & CML & $\mathrm{F}$ & 50 & 126 & 97 & 449 & Yes* & + & - & - \\
\hline 4 & $\mathrm{CML}$ & M & 50 & 69 & 106 & 320 & No & - & - & - \\
\hline 5 & CML & $M$ & 46 & 70 & 130 & 194 & No & - & - & + \\
\hline 6 & CML & $\mathrm{F}$ & 63 & 127 & 122 & 448 & No & - & - & + \\
\hline 7 & CML & $\mathrm{F}$ & 44 & 7.4 & 116 & 156 & Yes $^{\#}$ & - & + & + \\
\hline 8 & CML & $M$ & 60 & 221 & 77 & 55 & No & - & - & + \\
\hline 9 & CML & $M$ & 59 & 25 & 120 & 220 & No & - & - & + \\
\hline 10 & CML & $\mathrm{F}$ & 63 & 60 & 105 & 200 & No & - & - & + \\
\hline 11 & CMGM & M & 59 & 9.5 & 124 & 436 & No & - & + & - \\
\hline 12 & CMGM & $\mathrm{F}$ & 60 & 8.1 & 139 & 615 & No & - & + & - \\
\hline 13 & CMGM & $M$ & 76 & 23.5 & 169 & 1700 & No & - & + & - \\
\hline 14 & PV & $M$ & 45 & 13.4 & 166 & 899 & No & - & + & - \\
\hline 15 & PV & $M$ & 68 & 9.3 & 169 & 722 & No & - & + & - \\
\hline 16 & PV & $\mathrm{F}$ & 43 & 15.9 & 159 & 905 & No & - & + & - \\
\hline 17 & PTH & $\mathrm{F}$ & 73 & 9.3 & 157 & 1178 & No & - & + & + \\
\hline 18 & PTH & $\mathrm{F}$ & 77 & 13.1 & 142 & 810 & No & - & + & - \\
\hline 19 & PTH & $\mathrm{F}$ & 75 & 12.1 & 165 & 690 & No & - & + & - \\
\hline 20 & PTH & $\mathrm{F}$ & 84 & 8.2 & 123 & 1185 & No & - & + & - \\
\hline
\end{tabular}

CML, chronic myelocytic leukaemia; CMGM, chronic megakaryocytic granulocytic myelosis; PV, polycythaemia vera; PTH, primary thrombocythaemia; M, male; F, female; WBC, white blood cells; Hb, haemoglobin.

${ }^{\star}$ Interferon $\alpha$; ${ }^{*}$ Hydroxyurea.

"Exceeding normal bone marrow, which has < $1 \% \mathrm{c}-\mathrm{Mp1} / \mathrm{CD} 34$ positive mononuclear cells (data not shown). 
tive designation of $\mathrm{CMGM},{ }^{17}$ to distinguish early stages of the latter from essential thrombocythaemia (PTH). All patients with CML were proved to be Philadelphia chromosome positive by karyotyping; no substantial additional chromosomal abnormalities (including occurrence of $20 \mathrm{q}-$ ) were observed by karyotyping in our laboratory. ${ }^{18}$

REVERSE TRANSCRIPTASE POLYMERASE CHAIN REACTION (RT-PCR)

Total cellular RNA was extracted from heparinised peripheral blood samples by the RNAzol A method (Cinna Biotecx, Houston, Texas, USA). ${ }^{19}$ Blood mRNA integrity was checked by reverse transcription with random hexamer primers and consecutive PCR with primers for pyruvate dehydrogenase 1 $(\mathrm{PDH} 1)^{20}$ : sense $5^{\prime}$-GGT ATG GAT GAG GAC CTG GA-3' and antisense 5'-CTT CCA CAG CCC TCG ACT AA-3', giving rise to a 105 base pair (bp) fragment. Transcripts for c-mpl were detected using sense primer 5'-CTA GCT CCC AAG GCT TCT TC-3' (positions 927-946) and antisense primer 5'-GGC TCC AGC ACC TTC CAG TCC-3' (positions 1298-1319), ${ }^{21}$ producing a $392 \mathrm{bp}$ amplification product. Bone marrow mononuclear cells obtained from a patient with a normal bone marrow histopathology were used as a positive control. cDNA was synthesised using random hexamer primers $\left(\mathrm{pdN}_{6}\right)$ and Moloney murine leukaemia virus reverse transcriptase. PCR was performed using $5 \mu \mathrm{l}$ cDNA in a reaction containing a dNTP mix (2 $\mathrm{mM}$ dATP, $2 \mathrm{mM}$ dCTP, $2 \mathrm{mM}$ dGTP, and $2 \mathrm{mM}$ dTTP), reaction buffer (at a final concentration of $50 \mathrm{mM} \mathrm{KCl}, 10 \mathrm{mM}$ Tris/ $\mathrm{HCl}$, and $1.5 \mathrm{mM} \mathrm{MgCl}_{2}$ ), and $1.5 \mu \mathrm{l} \mathrm{Taq}$ polymerase (all reagents Boehringer Mannheim, Mannheim, Germany) in a final volume of $40 \mu \mathrm{l}$. Cycling conditions for PDH1 and c-mpl were $94^{\circ} \mathrm{C}$ for one minute, $68^{\circ} \mathrm{C}$ for one minute, and $72^{\circ} \mathrm{C}$ for one minute repeated 35 times, with an additional final extension at $72^{\circ} \mathrm{C}$ for five minutes. The PCR products $(8 \mu \mathrm{l}$ aliquots) were electrophoresed through a $2 \%$ agarose gel, stained with ethidium bromide, and visualised under UV light.

IMMUNOFLUORESCENCE

For double immunofluorescence staining of bone marrow aspirates, cytological preparations were fixed, washed in phosphate buffered saline (PBS), and blocked with normal rabbit serum. Slides were then incubated with a monoclonal antibody against c-Mpl (final concentration $0.1 \mu \mathrm{g} / \mathrm{ml}$; Genzyme, Cambridge,

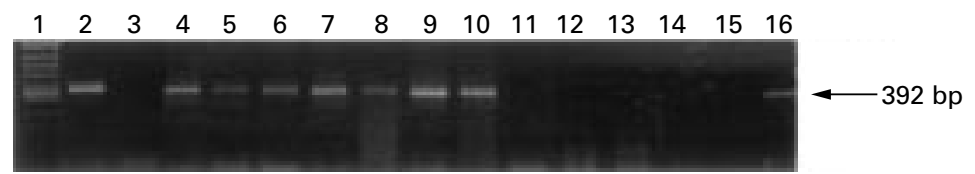

Figure 1 Expression of c-mpl thrombopoietin receptor $m R N A$ in the peripheral blood of patients with chronic myeloproliferative disorders. Total $R N A$ was subjected to reverse transcriptase polymerase chain reaction analysis with oligonucteotide primers amplifying c-mpl. Transcripts were detected in all patients with chronic myelocytic leukaemia (CML; lanes 4-8, five of 10 samples are shown), whereas only two patients with polycythaemia vera (PV, lanes 9-14), and one patient with primary thrombocythaemia (PTH, lanes 15 and 16) had c-mpl mRNA. Lane 1, molecular weight marker; lane 2, positive control; lane 3, negative control.
USA) for 30 minutes at room temperature, followed by a fluorescence (Cy3) labelled antimouse antibody (Jackson Immunoresearch, West Grove, Pennsyivania, USA). Cells were then incubated with a fluorescein isothiocyanate (FITC) conjugated monoclonal antiCD34 antibody (Pharmingen, Hamburg, Germany) overnight at $4^{\circ} \mathrm{C}$, washed, and counterstained. Two hundred mononuclear bone marrow cells were evaluated under a fluorescence microscope.

STATISTICAL ANALYSIS

To assess significance, the $\chi^{2}$ test was used wherever applicable.

\section{Results}

PERIPHERAL BLOOD c-mpl mRNA EXPRESSION In patients with CMPD, a total of 13 of 18 peripheral blood samples were positive for c-mpl transcripts, showing an amplification product of the expected size of $392 \mathrm{bp}$ (fig 1). By contrast, expression of c-mpl was not detected in any of the peripheral blood mononuclear cell samples obtained from healthy controls (eight, not shown).

All samples obtained from patients with Philadelphia chromosome positive CML were positive for c-mpl transcripts (10 of 10), regardless of white blood cell counts, platelet counts, or current treatment. By contrast, only two of six patients with PV and one of two patients with PTH had c-mpl transcripts. There was no correlation between peripheral blood c-mpl mRNA expression and platelet counts in the 18 patients studied. In addition, white blood cell counts did not correlate with c-mpl expression (table 1).

In summary, peripheral blood c-mpl mRNA expression occurred significantly more frequently in Philadelphia chromosome positive CML when compared with PV and PTH $\left(p \leqslant 0.008 ; \chi^{2}\right.$ test $)$.

\section{c-Mpl EXPRESSING HAEMATOPOIETIC}

PROGENITORS IN THE BONE MARRROW

In bone marrow aspirates obtained from patients lacking histopathological abnormalities, which were used as controls, the percentage of $\mathrm{c}-\mathrm{Mpl}$ expressing mononuclear cells coexpressing CD34 did not exceed 1\% (data not shown). In patients with CMPD, an increased number of c-Mpl positive haematopoietic progenitors $(>1 \%)$ was seen in eight of 20 samples (table 2 ).

Seven of 10 patients with Philadelphia chromosome positive CML had an increase of c-Mpl positive CD34 positive cells, as did one patient with PTH. None of the patients with CMGM or PV showed an increase in bone marrow progenitors coexpressing $\mathrm{c}-\mathrm{Mpl}$ and CD34.

As in our findings in the peripheral blood, the number of c-Mpl expressing CD34 positive haematopoictic cells significantly increased in Philadelphia chromosome positive CML when compared with Philadelphia chromosome negative disease entities ( $\mathrm{p} \leqslant 0.05 ; \chi^{2}$ test).

In all patients, trephine biopsies of the bone marrow were analysed simultaneously. All 
increases of c-Mpl expressing bone marrow progenitors were found not to correlate with either an increased number of bone marrow megakaryocytes or with thrombocythaemic peripheral blood cell counts. By contrast, increased bone marrow megakaryocytes and thrombocythaemic blood cell counts were seen predominantly in patients with CMGM, PV, and $\mathrm{PTH}$, who mainly had physiological numbers of c-Mpl positive haematopoietic progenitors. There was a tendency towards raised peripheral blood platelet counts in patients with increased bone marrow megakaryocytes $\left(\mathrm{p} \leqslant 0.055 ; \chi^{2}\right.$ test). Bone marrow fibrosis was found in one patient with CML who did not have raised bone marrow megakaryocytes or c-Mpl positive CD34 positive mononuclear bone marrow cells.

\section{Discussion}

Chronic myeloproliferative disorders arise from the clonal expansion of a single pluripotent haematopoietic cell but show a large degree of heterogeneity in terms of blood counts, bone marrow histopathology, and the clinical course of disease. Abnormal megakaryopoiesis is found frequently in the bone marrow of patients with CMPD, often associated with thrombocythaemic cell counts. Characteristic histological differences in megakaryocytic morphology and distribution are recognised and permit the distinction of patients with and without the Philadelphia chromosome. ${ }^{2}$ The c-Mpl throimbopoietin receptor and its ligand (thrombopoietin) are major regulators of normal megakaryopoiesis and platelet production, and may also be involved in abnormal megakaryopoiesis in CMPD, as suggested by experimental data. ${ }^{1315}{ }^{16}$ However, little is known about the differential expression of the c-mpl gene in patients with CMPD and its potential role in the pathobiology of these disorders.

In our study, the rationale for analysing peripheral blood samples for c-mpl gene expression is based on numerous reports showing that circulating megakaryocyte progenitors may induce spontaneous in vitro megakaryocyte colony formation, which is frequently found in CMPD..$^{5-816}$ Because megakaryocyte progenitors as well as multilineage precursors have been reported to express the c-mpl gene, ${ }^{22}{ }^{23}$ peripheral blood mononuclear cells from patients with CMPD should express c-mpl transcripts, at least those from patients presenting with thrombocythaemic cell counts, as suggested by Kobayashi et al. ${ }^{24}$ In contrast to the expected results, our study revealed c-mpl mRNA in only a small proportion of patients with Philadelphia chromosome negative disorders and a significantly higher expression of c-mpl transcripts in Philadelphia chromosome positive CML. Although we did not evaluate circulating megakaryocytic precursors on a cellular level, we conclude that expression of the c-mpl receptor gene is impaired in PV and PTH, rather than increased in CML. Our data confirm recent results by Moliterno et al, ${ }^{25}$ who demonstrated reduced expression of the thrombopoietin receptor in megakaryocytes and platelets of patients with PV and idiopathic myelofibrosis, which is considered to be an advanced stage of CMGM. ${ }^{2}$ The authors also reported reduced thrombopoietin mediated tyrosine phosphorylation of platelet proteins in PV, which was absent in CML and haematological disorders unrelated to CMPD. Our data suggest reduced transcription of the c-mpl gene as a possible mechanism in the decrease of thrombopoietin receptor expression and function in PV. However, differences in tyrosine phosphorylation of platelet protein between PV and CML may not be based solely on sustained thrombopoietin receptor expression in CML, because tyrosine phosphorylation can also occur by Bcr-Abl kinase, which is constitutively activated in the malignant CML clone. ${ }^{26}$

As in our findings in peripheral blood, the number of c-Mpl positive haematopoietic progenitors in the bone marrow, as characterised by coexpression of $\mathrm{c}-\mathrm{Mpl}$ and $\mathrm{CD} 34$, was significantly lower in CMGM, PV, and PTH when compared with CML. Surprisingly, most patients with Philadelphia chromosome negative CMPD presented with thrombocythaemic cell counts and increased numbers of bone marrow megakaryocytes in the face of normal levels of $\mathrm{c}-\mathrm{Mpl}$ positive haematopoietic progenitors. The relatively low incidence of increased bone marrow megakaryocytes in CML, in contrast to the high frequency of c-Mpl positive haematopoietic progenitors, may be related to shifts in the haematopoietic progenitor cell pool, as suggested recently. ${ }^{26}$

With respect to morphological features, PV and other Philadelphia negative CMPD frequently present with predominantly large and hypersegmented bone marrow megakaryocytes showing an increased nuclear ploidy, ${ }^{27}$ which strongly suggests thrombopoietin mediated terminal maturation. ${ }^{28}$ It is not understood how impaired c-Mpl receptor expression can give rise to a mature appearing phenotype of bone marrow megakaryocytes and thrombocythaemic cell counts, respectively. Because thrombopoietin concentrations have been reported not to be increased in CMPD when compared with reactive thrombocytosis ${ }^{29}$ other cytokines involved in the regulation of megakaryopoiesis might play a role. More speculatively, the underlying genetic aberration in Philadelphia chromosome negative disorders ${ }^{30}$ may give rise to regulatory pathways that allow megakaryocytic differentiation independent of the c-mpl/ thrombopoietin system.

Further studies are warranted to elucidate the role of decreased c-mpl gene expression in the natural history of Philadelphia negative disorders and the relevance of $\mathrm{c}-\mathrm{Mpl} /$ thrombopoietin in CMPD in general.

\footnotetext{
1 Buhr T, Georgii A, Schuppan 0, et al. Histologic findings in bone marrow biopsies of patients with thrombocythemic cell counts. Ann Hematol 1992;64:286-91.

2 Georgii A, Buhr T, Buesche G, et al. Classification and staging of $\mathrm{Ph}$-negative myeloproliferative disorders by histopathology from bone marrow biopsies. Luk Lymphoma 1996;22:15-29.

3 Nafe R, Georgii A, Kaloutsi V, et al. Planimetric analysis of megakaryocytes in the four main groups of chronic myeloproliferative disorders. Virchows Arch B Cell Pathol 1991;61: prolifera.

4 Kaloutsi V, Fritsch RS, Buhr T, et al. Megakaryocytes in chronic myeloproliferative disorders: numerical density
} 
correlated between different entities. Virchows Archiv A Pathol Anat Histopathol 1991;418:493-7.

5 Hibbin JA, Nioku OS, Matutes E, et al. Myeloid progenitor cells in the circulation of patients with myelofibrosis and other myeloproliferative disorders. Br f Haematol 1984;57: other 503 .

6 Juvonen E, Partanen S, Ruutu T. Colony formation by megakaryocytic progenitors in essential in thrombocythemia. $B$ f Haematol 1987;66:161-4.

7 Battegay EJ, Thomssen C, Nissen C, et al. Endogenous megakaryocyte colonies from peripheral blood in precurso cell cultures of patients with myeloproliferative disorders. Eur f Haematol 1989;42:321-6.

8 Juvonen E, Ikkala E, Oksanen K, et al. Megakaryocyte and erythroid colony formation in essential thrombocythemia and reactive thrombocytosis: diagnostic value and correlation to complications. Br f Haematol 1993;83:192-7.

9 Kaushansky K. Thrombopoietin. N Engl f Med 1998;339: 746-54.

10 Borge OJ, Ramsfjell V, Cui L, et al. Ability of early acting cytokines to directly promote survival and suppress apoptosis of human primitive $\mathrm{CD} 34^{+} \mathrm{CD} 38^{-}$bone marrow apoptosis of human primitive CD $34^{+} \mathrm{CD} 38$ bone marrow cells with multilineage potential at the single-cell

11 Vigon 1, Mornon JP, Cocault L, et al. Molecular cloning and characterization of MPL, the human homolog of the v-mp oncogene: identification of a member of the hematopoietic growth factor receptor superfamily. Proc Natl Acad Sci USA 1992;89:5640-4.

12 Souyri M, Vigon I, Penciolelli JF, et al. A putative truncated cytokine receptor gene transduced by the myeloproliferative leukemia virus immortalizes hematopoietic progenitors. Cell 1990;63:1137-47.

13 Alexander WS, Metcalf D, Dubb AR. Point mutation within a dimer interface homology domain of c-mpl induce constitutive receptor activity and tumorigenicity. EMBO $\mathcal{F}$ 1995; 14:5569-78

14 Ulich TR, del Castilloo J, Senaldi G, et al. Systemic hematological effects of PEG-rHuMGDF-induced megakaryocyte logical effects of PEG-rHuMGDF-induced m
hyperplasia in mice. Blood 1996;87:5006-15.

15 Yan XQ, Lacey D, Hill D, et al. A model of myelofibrosis and osteosclerosis in mice induced by overexpressing thrombopoietin (mpl ligand): reversal of disease by bone marrow (1960:88:402-9.

$16 \mathrm{Li} \mathrm{Y,} \mathrm{Hetet} \mathrm{G,} \mathrm{Kiladjian} \mathrm{JJ,} \mathrm{et} \mathrm{al.} \mathrm{Protooncogene} \mathrm{c-mpl} \mathrm{is}$ involved in spontaneous megakaryocytopoiesis in myeloproliferative disorders. Br f Haematol 1996;92:60-6.
17 Georgii A, Vykoupil KF, Thiele J. Chronic megakaryocytic granulocytic myelosis-CMGM. Virchows Arch A Pathol granulocytic myelosis-CMGM. Virc

18 Nolte M, Werner M, Ewig M, et al. Demonstration of the Philadelphia translocation by fluorescence in situ hybridization in paraffin sections and identification of aberrant cells by a combined FISH/immunophenotyping approach. Histopathology 1995;26;433-37.

19 Chomczynski P, Saachi N. Single-step method of RNA isoation by acid guanidinium thiocyanate-phenol-chloroform extraction. Anal Biochem 1987;162:156-9.

20 Rolfs A, Schuller I, Finckh U, et al (eds). Reverse transcription/PCR (RT-PCR). In: PCR: clinical diagnostics and research. Berlin: Springer-Verlag, 1992:99-111.

21 Columbyova L, Loda M, Scadden DT. Thrombopoietin receptor expression in human cancer cell lines and primary tissues. Cancer Res 1995;55:3509-12.

22 Debili N, Wendling F, Cosman D, et al. The mpl receptor is expressed in the megakaryocytic lineage from late progeniexpressed in the megakaryocytic lineage

23 Methia N, Louache F, Vallichenker W, et al. Oligodeoxynucleotides antisense to the proto-oncogene c-mpl specifically cleotides antisense to the proto-oncogene c-mpl specifically 401 .

24 Kobayashi S, Teramura M, Hoshino S, et al. Circulating megakaryocyte progenitors in myeloproliferative disorders are hypersensitive to interleukin-3. Br f Haematol 1993;83: $539-44$.

25 Moliterno AR, Hankins WD, Spivak JL. Impaired expression of the thrombopoietin receptor by platelets from patients with polycythemia vera. $N$ Engl f Med 1998;338: $572-80$

26 Gordon MY, Goldman JM. Cellular and molecular mechanisms in chronic myeloid leukaemia: biology and treatment. Br f Haematol 1996;95:10-20.

27 Jacobson S, Carneskog J, Ridell B, et al. Flow cytometric analysis of megakaryocyte ploidy in chronic myeloproliferative disorders and reactive thrombocytosis. Eur f Haematol 1996;56:287-92.

28 Kaushansky K, Lok S, Holly RD, et al. Promotion of megakaryocyte progenitor expansion and differentiation by megakaryocyte progenitor expansion and differentiation

29 Cerutti A, Custodi P, Duranti M, et al. Thrombopoietin levels in patients with primary and reactive thrombocytosis. $\mathrm{Br}$ els in patients with primary

30 Green AR. Pathogenesis of polycythemia vera. Lancet 1996; 347:844-5. 